Analytical Methods

\title{
Towards honey authentication: Differentiation of Apis mellifera subspecies in European honeys based on mitochondrial DNA markers
}

\author{
Sónia Soares $^{\mathrm{a}, 1}$, Liliana Grazina ${ }^{\mathrm{a}, 1}$, Isabel Mafra ${ }^{\mathrm{a}, *}$, Joana Costa ${ }^{\mathrm{a}}$, M. Alice Pinto ${ }^{\mathrm{b}}$, \\ M. Beatriz P.P. Oliveira ${ }^{\mathrm{a}}$, Joana S. Amaral ${ }^{\mathrm{a}, \mathrm{b}, *}$ \\ ${ }^{\text {a }}$ REQUIMTE-LAQV, Faculdade de Farmácia, Universidade do Porto, Rua de Jorge Viterbo Ferreira, 228, 4050-313 Porto, Portugal \\ ${ }^{\mathrm{b}}$ Centro de Investigação de Montanha (CIMO), Instituto Politécnico de Bragança, Portugal
}

\section{A R T I C L E I N F O}

\section{Keywords:}

Honey

Honeybee DNA

HRM analysis

Authenticity

Apis mellifera subspecies

\begin{abstract}
A B S T R A C T
Honey is the natural sweet substance produced by Apis mellifera honeybees in Europe. Depending on the country/region, the $A$. mellifera subspecies native to Europe belong to three different lineages: A (A. $m$. iberiensis), M (A. m. iberiensis and A. m. mellifera) and C (A. m. ligustica and A. m. carnica). In this work, two DNAbased approaches were developed with the aim of entomological authentication of European honeys. A cytb specific PCR assay was proposed to identify A-lineage honeybees, while a second method based on real-time PCR coupled to high resolution melting analysis targeting the COI gene was developed to differentiate C- and Mlineages honeybees. The proposed methodologies were validated successfully with honeys of known origin and applied to the entomological authentication of 20 commercial samples from different European countries. The results highlight the predominance of honeys from C-lineage honeybees in Europe, except in Iberian Peninsula countries (honey from A-lineage honeybees).
\end{abstract}

\section{Introduction}

As defined by the Codex Alimentarius, honey is the natural sweet substance produced by honeybees (FAO, 2001). According to the European Union legislation (Directive 2014/63/EU), honey should be produced by Apis mellifera, which is the only honeybee species native to Europe, being also naturally found in Africa and the Middle East (Ruttner, 1988). Presently, over 27 different subspecies of A. mellifera are known (Meixner et al., 2013; Ruttner, 1988), which have been grouped into three major evolutionary lineages, concurrently supported by morphology (Ruttner, 1988) and mitochondrial (mt) DNA (Garnery, Cornuet, \& Solignac, 1992): the African (A), the western European (M) and the eastern European (C). In continental Europe, mtDNA belonging to the African lineage is present in the native honeybee subspecies of Iberian Peninsula, A. m. iberiensis, which is found across most of the peninsula. The A-lineage is gradually replaced by the M-lineage towards the northeastern part of Iberian Peninsula, reaching high frequencies close to the Pyrenees (Chávez-Galarza et al., 2017). The sister subspecies of $A$. m. iberiensis, namely the Dark honeybee A. m. mellifera, only carries mtDNA of M ancestry (Garnery et al., 1998; Pinto et al., 2014). The native distribution of $A$. $m$. mellifera ranges from the
Pyrenees to Scandinavia, and from the British Isles to the Ural Mountains (Ruttner, 1988). Subspecies from lineage C are naturally found in a smaller geographical area comprising the Apennine and Balkan peninsulas (Ruttner, 1988). A larger number of subspecies belongs to this lineage, including the two most frequently used in commercial beekeeping worldwide: the Italian honeybee A. $m$. ligustica and the Carniolan honeybee $A$. $m$. carnica (Meixner et al., 2013; Pinto et al., 2014). This notable diversification and the distribution of subspecies across Europe mainly results from the isolation of honeybee populations after the Last Glacial Maximum. During this period, the mountain chains of the Pyrenees, the Alps and the Balkans acted as geographic barriers, along with the species adaptation to a wide range of environments (Chávez-Galarza et al., 2017; De la Rúa, Jaffé, Dall'Olio, Muñoz, \& Serrano, 2009). However, during the last decades, the native distribution of the European honeybees has been facing increasing challenges mainly because of the mass importation of honeybee colonies and the deliberate introduction of foreign queens (Pinto et al., 2014). For example, in Northern Europe, the Dark honeybee has been partially replaced by foreign honeybees, such as $A$. m. ligustica due to its large honey storing ability, docility and adaptability to a wide range of climatic conditions (Dall'Olio, Marino, Lodesani, \& Moritz, 2007; Jensen,

\footnotetext{
* Corresponding authors at: REQUIMTE-LAQV, Faculdade de Farmácia, Universidade do Porto, Rua de Jorge Viterbo Ferreira, 228, 4050-313 Porto, Portugal.

E-mail addresses: isabel.mafra@ff.up.pt (I. Mafra), jamaral@ipb.pt (J.S. Amaral).

${ }^{1}$ Both authors contributed equally for the work.
} 
Palmer, Boomsma, \& Pedersen, 2005). In addition, in some regions of France, the Dark honeybee has been highly introgressed by imported breed stock of C-lineage ancestry (Pinto et al., 2014). This introgression is highly detrimental as it leads to losses of locally-adapted gene complexes, thereby threatening the native species in their natural ranges (De la Rúa et al., 2009). Native honeybee subspecies in Europe represent reservoirs of unique combinations of genes, being well adapted to local conditions. Accordingly, in an attempt to safeguard this important genetic legacy, we are witnessing an emerging conservation movement to protect the native diversity from the admixture of divergent honeybee subspecies, which is frequently promoted by beekeepers to increase the economic performance of the colonies (De la Rúa et al., 2009; Meixner et al., 2010; Pinto et al., 2014). In this context, several conservation programs and protected areas are being established for some subspecies that are being recognised as threatened in its native range, such as the Dark honeybee (De la Rúa et al., 2009; Pinto et al., 2014). In this case, for beekeepers to valorise hive products, it is of major importance to authenticate the entomological origin of honey. Additionally, several European honeys with protected designation of origin (PDO) specifically refer the honeybee subspecies that should be used for their production (DOOR, 2017). This is the case of several French, Italian, Portuguese, Polish and Slovenian PDO honeys, as presented in Table S1 (supplementary material). Regarding the remaining PDO honeys, although the honeybee subspecies is not specified, it is expected that they are produced by the native honeybees since they should be produced, processed and prepared in specific geographical areas using the ingredients from the region concerned (European Commission, 2017). Therefore, there is a need for developing new methodologies that allow the entomological authentication of honey.

Since the economic and nutritional value of honey is mainly established taking into account its botanical and geographical origins, most works published so far have been focusing on those issues (Soares et al., 2018a; Soares, Amaral, Oliveira, \& Mafra, 2017). However, as referred, the entomological source can indirectly give information about the geographical origin of honey. Despite this, only few studies have attempted the entomological identification of honey, either based on protein (Ramón-Sierra, Ruiz-Ruiz, \& de la Luz Ortiz-Vázquez, 2015) or DNA analysis (Kek, Chin, Tan, Yusof, \& Chua, 2017; Prosser \& Hebert, 2017; Soares et al., 2018b). For this purpose, DNA-based methods are considered as being the most suitable tools since they allow unequivocal species identification. Prosser and Hebert (2017) established the entomological origins of honey produced from A. mellifera and Melipona beecheii using metabarcoding of cytochrome $c$ oxidase subunit I (COI) gene. Kek et al. (2017) identified the bee species $A$. dorsata, A. mellifera, A. cerana and Heterotrigona itama in honey samples based on forensically informative nucleotide sequencing (FINS) targeting the COI and 16S rRNA mitochondrial genes. Soares et al. (2018b) were able to differentiate the Asian (A. cerana) and European (A. mellifera) honeybee species in honeys using high resolution melting (HRM) analysis targeting the 16S rRNA gene. To our knowledge, there is no report about the differentiation of European subspecies of $A$. mellifera in honeys. Thus, this work aims the development of molecular-based approaches, namely species-specific polymerase chain reaction (PCR) and real-time PCR with HRM analysis, for the entomological identification/ authentication of honey produced by the most commonly used European honeybee subspecies, belonging to different lineages. To that end, several honeybee specimens of the most representative subspecies used in European honeys, including PDO, namely A. m. iberiensis (A and $\mathrm{M}$ lineages), A. m. mellifera (M lineage), A. m. ligustica (C lineage) and A. $m$. carnica (C lineage) were used for method development. The developed methodologies were further applied to the analysis of authentic and commercial honeys.
Table 1

Authentic and commercial honey samples from different European countries analysed by end-point PCR targeting a universal marker and the cytb gene of $A$. m. iberiensis.

\begin{tabular}{|c|c|c|c|c|}
\hline \multirow{2}{*}{$\begin{array}{l}\text { Honey } \\
\text { sample }\end{array}$} & \multirow{2}{*}{$\begin{array}{l}\text { Country of } \\
\text { acquisition }\end{array}$} & \multirow[t]{2}{*}{ Labelled origin } & \multicolumn{2}{|c|}{ End-point PCR ${ }^{*}$} \\
\hline & & & $18 S E U^{\mathrm{a}}$ & Apis $2^{b}$ \\
\hline A & Spain & $\begin{array}{l}\text { Borriol (M-lineage authentic } \\
\text { honey) }\end{array}$ & + & - \\
\hline B & Italy & $\begin{array}{l}\text { Monteu Roero (C-lineage } \\
\text { authentic honey) }\end{array}$ & + & - \\
\hline $\mathrm{C}$ & Portugal & $\begin{array}{l}\text { Algarve (A-lineage authentic } \\
\text { honey) }\end{array}$ & + & + \\
\hline $\mathrm{D}$ & Spain & $\begin{array}{l}\text { Murcia (A-lineage authentic } \\
\text { honey) }\end{array}$ & + & + \\
\hline 1 & Croatia & $\begin{array}{l}\text { EU and non-EU, Donji } \\
\text { Dragonožec, Hrvatska }\end{array}$ & + & - \\
\hline 2 & Denmark & Helsingør & + & - \\
\hline 3 & Denmark & Nationalpark Thy & + & - \\
\hline 4 & France & $\begin{array}{l}\text { Pyrenees, Chemin de } \\
\text { Berdoulou }\end{array}$ & + & - \\
\hline 5 & France & Provence (PGI honey) & + & - \\
\hline 6 & France & Provence (PGI honey) & + & - \\
\hline 7 & France & EU and non-EU, Maurecourt & + & - \\
\hline 8 & Italy & Riserva San Massimo, Milan & + & - \\
\hline 9 & Italy & $\begin{array}{l}\text { Monteu Roero (organic } \\
\text { honey) }\end{array}$ & + & - \\
\hline 10 & Italy & Centro-sud, Casabianca Asti & + & - \\
\hline 11 & Italy & Parco del Ticino, Milan & + & - \\
\hline 12 & Poland & $\begin{array}{l}\text { EU and non-EU, Poland, } \\
\text { Romania, Bulgaria, Ukraine }\end{array}$ & + & - \\
\hline 13 & Spain & Valencia & + & - \\
\hline 14 & Sweden & Haugen & + & - \\
\hline 15 & Sweden & Säffle & + & - \\
\hline 16 & Portugal & Bragança (PDO honey) & + & + \\
\hline 17 & Portugal & Castelo Branco & + & + \\
\hline 18 & Portugal & Coimbra (PDO honey) & + & + \\
\hline 19 & Portugal & Vila Real & + & + \\
\hline 20 & Spain & Málaga & + & + \\
\hline
\end{tabular}

* Amplification was performed using primers.

a 18SEU-F/18SEU-R targeting eukaryotes,

b Apis2-F/Apis2-R targeting A. m. iberiensis of A lineage.

\section{Materials and methods}

\subsection{Samples}

Voucher specimens of honeybee individuals from different subspecies of $A$. mellifera, including the most representative of European honey production, were used in this work: the C-lineage $A$. $m$. carnica from Serbia $(\mathrm{n}=3)$ and Croatia $(\mathrm{n}=1)$; the C-lineage $A$. $m$. ligustica from Italy $(\mathrm{n}=4)$; the A-lineage $A . m$. iberiensis from Portugal $(\mathrm{n}=24)$ and Spain $(\mathrm{n}=5)$; the M-lineage $A$. $m$. iberiensis from Spain $(\mathrm{n}=7)$; the M-lineage A. m. mellifera from France $(\mathrm{n}=4)$, Netherlands $(\mathrm{n}=1)$, Scotland $(n=1)$ and Norway $(n=1)$. Additionally, C-lineage commercial Buckfast honeybees $(n=3)$ collected in Portugal were also used in this work. All honeybee individuals were collected from distinct apiaries and their tissues were stored in absolute ethanol at $-20^{\circ} \mathrm{C}$.

Authentic honey samples with known entomological origin were collected from apiaries in Italy, Spain and Portugal, corresponding to Clineage A. m. ligustica, M-lineage A. m. iberiensis, and A-lineage A. $m$. iberiensis, respectively. These samples were collected by beekeepers from known hives. Additionally, 20 honey samples from different European countries were acquired in local and international markets (Table 1).

\subsection{DNA extraction}

Honeybee tissues were homogenised in reaction tubes $(2 \mathrm{~mL})$, stored at $-20{ }^{\circ} \mathrm{C}$ overnight and submitted to DNA extraction using the Wizard 
method, as described by Mafra et al. (2008). To the sample tissues, $860 \mu \mathrm{L}$ of extraction buffer TNE $(10 \mathrm{mM}$ Tris, $150 \mathrm{mM} \mathrm{NaCl}, 2 \mathrm{mM}$ EDTA, $1 \%$ SDS), $100 \mu \mathrm{L}$ of $5 \mathrm{M}$ guanidine hydrochloride solution and $40 \mu \mathrm{L}$ proteinase $\mathrm{K}$ solution $(20 \mathrm{mg} / \mathrm{mL})$ were added. After vigorous vortexing, the mixture was incubation at $60^{\circ} \mathrm{C}$ for $3 \mathrm{~h}$, with occasional stirring, the centrifuged ( $15 \mathrm{~min}, 18,514 \mathrm{~g}$ ) and $500 \mu \mathrm{L}$ of the supernatant were mixed with $1 \mathrm{~mL}$ of Wizard ${ }^{\circledR}$ DNA purification resin (Promega, Madison, WI, USA). A $2 \mathrm{~mL}$ syringe was mounted on the column and the mixture was pushed with the plunger through the column. The DNA-resin mixture was washed with $2 \mathrm{~mL}$ isopropanol solution $(80 \% \mathrm{v} /$ v). The column was dried for $5 \mathrm{~min}$ at room temperature and mounted on a new reaction tube. The DNA was eluted by the addition of $100 \mu \mathrm{L}$ of Tris-EDTA buffer ( $10 \mathrm{mM}$ Tris, $1 \mathrm{mM}$ EDTA) at $70{ }^{\circ} \mathrm{C}$, incubation for $1 \mathrm{~min}$ and centrifugation (1 min, 10,000g).

Additionally, for sequencing purposes, total DNA was extracted with the phenol/chloroform isoamyl alcohol (25:24:1) method (Sambrook, Fritsch, \& Maniatis, 1989) from the thorax of honeybee individuals (namely for A. m. mellifera, A. m. carnica, A. m. ligustica, A. m. iberiensis (A- and M-lineages)).

Regarding honey samples, before DNA extraction, a pre-treatment was performed, as previously described (Soares et al., 2018b) to discard possible interferences. DNA was then extracted from the obtained pellet using NucleoSpin ${ }^{\circledR}$ Plant II (Macherey-Nagel, Düren, Germany) kit, according to the manufacturer instructions with some minor modifications, as described by Soares, Amaral, Oliveira, and Mafra (2015). All extractions were performed in duplicate for each sample and the extracts were kept at $-20^{\circ} \mathrm{C}$ until further analysis.

The yield and purity of the extracts were assessed by UV spectrophotometry using a SynergyHT multi-mode microplate reader (BioTek Instruments, Inc., Vermont, USA) with a Take 3 micro-volume plate accessory. The absorbance was measured at 260 and $280 \mathrm{~nm}$ in order to estimate DNA content and purity using the nucleic acid quantification protocol with sample type defined for double-strand DNA in the Gen5 data analysis software version 2.01 (BioTek Instruments, Inc., Vermont, USA). The quality of extracted DNA was further evaluated by electrophoresis in a $1.0 \%$ agarose gel containing Gel Red $1 \times$ (Biotium, Hayward, CA, USA) for staining and carried out in SGTB $1 \times$ (GRiSP, Research Solutions, Porto, Portugal) for $20 \mathrm{~min}$ at $200 \mathrm{~V}$. The agarose gel was visualised under a UV light tray Gel Doc ${ }^{\mathrm{TM}}$ EZ System (Bio-Rad Laboratories, Hercules, CA, USA) and a digital image was obtained with Image Lab software version 5.1.

\subsection{Selection of the target gene and oligonucleotide primers}

The DNA sequences corresponding to mtDNA genes encoding for the cytochrome $b(c y t b)$ and for the COI of A. mellifera subspecies were obtained from mitogenomes of individuals representing three lineages (A, M and C). Whole genome sequencing was performed using the Illumina HiSeq 2500 platform. The 2 X150 paired-end sequence reads were mapped against the mitochondrial reference honeybee genome Amel_4.5. The reads were only used after applying several filters to reduce poor mapping and spurious positions. The single nucleotide polymorphisms (SNP), that had more than two alleles, showed a quality score $<50$ and were called in less than $90 \%$ of the mitogenomes, were removed. To help identifying spurious SNP in mtDNA, data was intentionally mis-specified to be diploid in the SNP calling process using FreeBayes (Garrison \& Marth, 2012). The heterozygous positions were, thus, removed from the dataset as they do not represent true SNP. Some problematic SNP were identified by more than one filter. Of the 795 SNP initially identified, only 645 passed the filtering criteria and were retained for subsequent analysis. The bcftools, implemented in the SAMtools software package (Li, Gao, Liu, \& Cai, 2009) to incorporate each variant into the reference mitogenome, were used.

Two sets of primers were designed: Apis2-F (TGT ACT ACC ATG AGG ACA AAT ATC A) and Apis2-R (ATT AAT TGA GAA CCC ACC TCA GAT) targeting the cytb gene to produce DNA fragments of $121 \mathrm{bp}$; and
Aml5-F (AGG ATC ATG AAT TAG CAA TG) and Aml5-R (GAA TGC TAT ATC AGG TGA TC) targeting the COI gene to obtain fragments of $151 \mathrm{bp}$. The design was performed using the software Primer-BLAST designing tool (http://www.ncbi.nlm.nih.gov/tools/primer-blast/). Primer properties and the absence of hairpins and self-hybridization were assessed using the software OligoCalc (http://www.basic. northwestern.edu./biotools/oligocalc.html). Primer specificity was assessed using the Primer-BLAST tool that allows revealing homologies in relation to all sequences available in the database (Genbank). The designed primers were synthesised by STABVIDA (Lisbon, Portugal).

\subsection{End-Point PCR}

The PCR amplifications were carried out in a total reaction volume of $25 \mu \mathrm{L}$, containing $2 \mu \mathrm{L}$ of DNA extract ( $10 \mathrm{ng}), 67 \mathrm{mM}$ Tris- $\mathrm{HCl}(\mathrm{pH}$ 8.8), $16 \mathrm{mM}$ of $\left(\mathrm{NH}_{4}\right)_{2} \mathrm{SO}_{4}, 0.1 \%$ of Tween $20,200 \mu \mathrm{M}$ of each dNTP, $1.0 \mathrm{U}$ of SuperHot Taq DNA Polymerase (Genaxxon Bioscience GmbH, Ulm, Germany), $2.0 \mathrm{mM}$ (with primers Apis2-F/Apis2-R) or $3.0 \mathrm{mM}$ (with primers Aml5-F/Aml5-R) of $\mathrm{MgCl}_{2}$ and $200 \mathrm{nM}$ of each primer. The reactions were performed in a thermal cycler MJ Mini ${ }^{\mathrm{TM}}$ Gradient Thermal Cycler (Bio-Rad Laboratories, USA) using the following programs: (i) initial denaturation at $95^{\circ} \mathrm{C}$ for $5 \mathrm{~min}$; (ii) 40 cycles at $95^{\circ} \mathrm{C}$ for $30 \mathrm{~s}, 61{ }^{\circ} \mathrm{C}$ or $51{ }^{\circ} \mathrm{C}$ (with primers Apis2-F/Apis2-R or Aml5-F/Aml5R) for $30 \mathrm{~s}$ and $72{ }^{\circ} \mathrm{C}$ for $30 \mathrm{~s}$; (iii) and a final extension at $72{ }^{\circ} \mathrm{C}$ for 5 min.

The amplified fragments were analysed by electrophoresis in a $1.5 \%$ agarose gel containing Gel Red $1 \times$ (Biotium, Hayward, CA, USA) for staining and carried out in SGTB $1 \times$ (GRiSP, Research Solutions, Porto, Portugal). The agarose gel was visualised under a UV light tray Gel Doc $^{\mathrm{TM}}$ EZ System (Bio-Rad Laboratories, Hercules, CA, USA) and a digital image was obtained with Image Lab software version 5.1. Each extract was amplified at least in duplicate assays.

\subsection{Real-time PCR and HRM analysis}

The real-time PCR assays were performed in $20 \mu \mathrm{L}$ of total reaction volume, containing $2 \mu \mathrm{L}$ of DNA extract $(10 \mathrm{ng}), 1 \times$ of SsoFast $^{\mathrm{TM}}$ Evagreen ${ }^{\circledR}$ Supermix (Bio-Rad Laboratories, USA) and $400 \mathrm{nM}$ of each primer Aml5-F/Aml5-R. The assays were carried out in a fluorometric thermal cycler CFX96 Real-time PCR Detection System (Bio-Rad, Hercules, CA, USA) using the following temperature programme: $95^{\circ} \mathrm{C}$ for $5 \mathrm{~min}, 50$ cycles at $95^{\circ} \mathrm{C}$ for $15 \mathrm{~s}, 50^{\circ} \mathrm{C}$ for $15 \mathrm{~s}$ and $72{ }^{\circ} \mathrm{C}$ for $25 \mathrm{~s}$, with the collection of fluorescence signal at the end of each cycle. Data were collected and processed using the software Bio-Rad CFX Manager 3.0. Each specimen and sample was amplified in four replicates in two independent assays.

For HRM analysis, PCR products were denatured at $95{ }^{\circ} \mathrm{C}$ for $1 \mathrm{~min}$ and then annealed at $50^{\circ} \mathrm{C}$ for 5 min to allow the correct annealing of the DNA duplexes. These two steps were followed by melting curve ranging from 60 to $90^{\circ} \mathrm{C}$ with temperature increments of $0.2^{\circ} \mathrm{C}$ every $10 \mathrm{~s}$ (Costa, 2013). The fluorescence data were acquired at the end of each melting temperature. The collected fluorescence data were processed using the Precision Melt Analysis Software 1.2 (Bio-Rad Laboratories, Hercules, CA, USA) to generate melting curves as a function of temperature and difference curves for easier visual identification of clusters. Cluster detection settings were defined targeting high sensitivity and threshold yields, with the melting curve shape sensitivity parameter being adjusted to a value $>98 \%$ and $\mathrm{Tm}$ difference threshold parameter set as a default value of 0.15 . DNA extracts were analysed in two independent assays using four replicates in each one.

\section{Results and discussion}

\subsection{Evaluation of extracted DNA}

The quality assessment of DNA extracts obtained from honeybee 
tissues showed, in general, high yields $(62.0-796.8 \mathrm{ng} / \mu \mathrm{L})$ and good purity (1.8-2.3). As expected, due to matrix complexity, the DNA extracts obtained from honey samples presented lower yields $(1.8-118.2 \mathrm{ng} / \mu \mathrm{L})$ and purity $(1.5-2.4)$. The results are in agreement with previous studies using the same DNA extraction methodology applied to similar samples (Soares et al., 2018b). Prior to DNA amplification with the newly designed primers, all honeybee and honey extracts were evaluated for their amplification capacity by means of PCR targeting a universal eukaryotic sequence (18S rRNA gene) with primers 18SEU-F/18SEU-R (Fajardo et al., 2008). All samples tested positively with the universal primers, confirming the absence of false negative results that could occur due to PCR inhibition (Tables 1 and 3).

\subsection{End-point PCR targeting cytb and COI genes}

In the present work, the COI barcode region was chosen because it has been preferred among the mitochondrial protein-coding genes as the core molecular diagnostic system for animal species identification (Hebert, Cywinska, Ball, \& deWaard, 2003), including honeybees (Prosser \& Hebert, 2017). The mitochondrial cytb gene was also selected due to its suitability demonstrated in animal species differentiation (Chen, Jiang, \& Qiao, 2012; Fernandes, Costa, Oliveira, \& Mafra, 2017). Accordingly, new primers were specifically designed in the regions of the COI (Aml5-F/Aml5-R) and cytb (Apis2-F/Apis2-R) genes to evaluate their capacity as potential makers for honeybee genotype differentiation (Figs. S1 and S2, supplementary material). The specificity of the new primers was firstly verified in silico by the use of the primer-BLAST tool and then confirmed experimentally against several DNA extracts from honeybee specimens belonging to the different $A$. mellifera subspecies under study (Figs. $1 \mathrm{~A}$ and $2 \mathrm{~A}$ ). Additionally, considering that plant DNA is also present in honey due to pollen grains (Soares et al., 2015), several plant species $(n=36)$, frequently described in melissopalinological analysis of monofloral and multifloral honeys, were also amplified with the proposed primers to check for any eventual crossreactivity. No amplification was obtained from all tested plant species with both primer sets (Table S2, supplementary material). The amplification capacity of DNA extracts from plants was first checked using
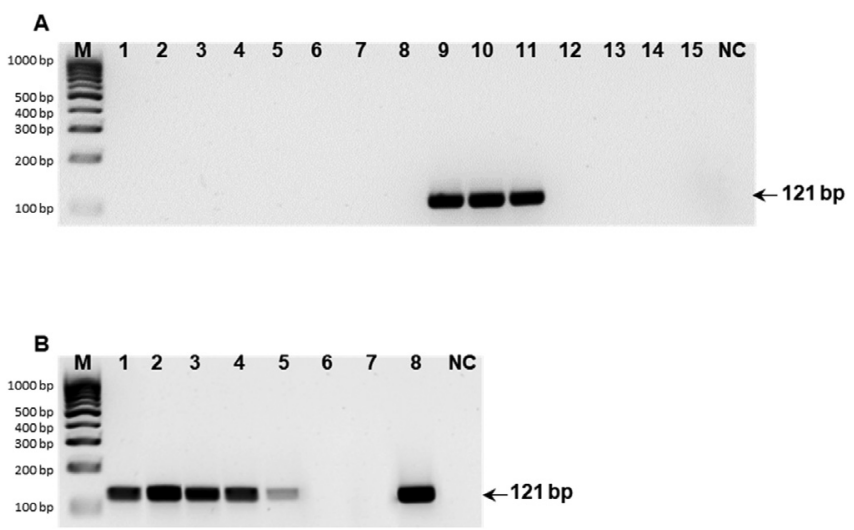

Fig. 1. Agarose gel electrophoresis of PCR products targeting the cytb gene with primers Apis2-F/Apis2-R applied to DNA extracts from different $A$. mellifera subspecies (A) and honey samples of different entomological origins (B). Legend A: lanes 1, 2 and 3, A. m. ligustica; lanes 4 and 5, A. m. carnica; lanes 6, 7 and 8, Buckfast; lanes 9, 10 and 11, A. m. iberiensis (A lineage); lanes 12 and 13, A. m. mellifera; lane 14 and 15, A. m. iberiensis (M lineage). Legend B: lane 1, PDO commercial honey from Bragança, Portugal; lane 2, authentic honey from A. m. iberiensis (A lineage), Portugal; lane 3, commercial honey from Castelo Branco, Portugal; lane 4, PDO commercial honey from Coimbra, Portugal; lane 5, authentic honey from A. m. iberiensis (A lineage), Spain; lane 6, authentic honey from A. m. iberiensis (M lineage), Spain; lane 7, authentic honey from $A$. m. ligustica, Italy; and lane 8, positive control (A. m. iberiensis (A lineage)). M, 100 bp DNA molecular marker (Bioron, Ludwigshafen, Germany); NC, negative control.
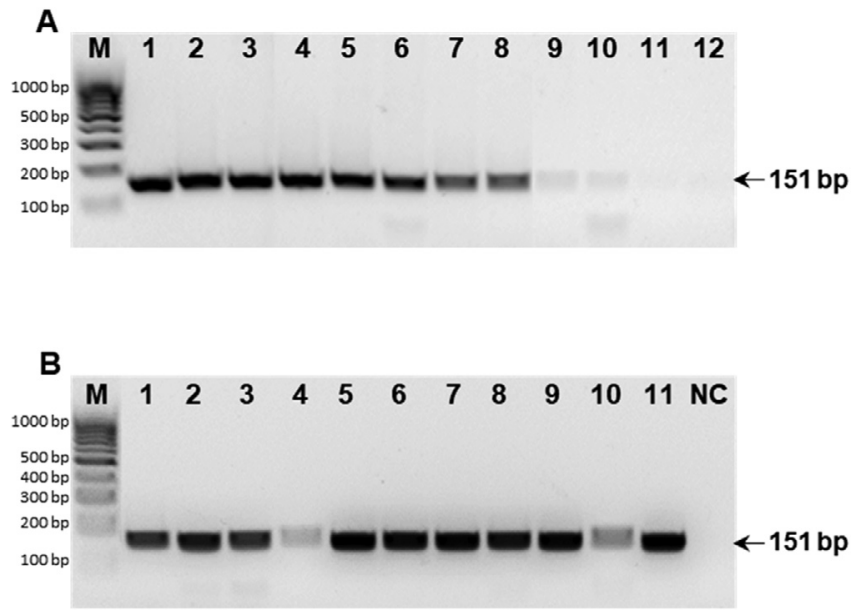

Fig. 2. Agarose gel electrophoresis of PCR products targeting the COI gene with primers Aml5-F/Aml5-R applied to DNA extracts from different A. mellifera subspecies (A) and honey samples of different entomological origins (B). Legend A: lanes 1 and 2, A. m. ligustica; lanes 3 and 4, A. m. carnica; lanes 5 and 6, Buckfast; lanes 7 and 8, A. m. iberiensis (A lineage) from Spain; lanes 9 and 10, A. m. iberiensis (M lineage); lanes 11 and 12, A. m. mellifera. Legend B: lane 1 , commercial honey from Italy (Monteu Roero); lane 2, commercial honey from France (Pyrenees); lane 3, commercial honey from Croacia; lane 4, commercial honey from Spain (Valencia); lane 5, commercial honey from France (Provence); lane 6, commercial honey from Denmark (Helsinger); lane 7, commercial honey from Sweden (Haugen); lane 8, commercial honey from Poland; lane 9, commercial honey from Italy (Milan); lane 10, authentic honey of M-lineage honeybee from Spain; lane 11, authentic honey of C-lineage honeybee from Italy. M, 100 bp DNA molecular marker (Bioron, Ludwigshafen, Germany); NC, negative control.

primers EG-F/EG-R targeting a universal eukaryotic gene (Villa, Costa, Oliveira, \& Mafra, 2017).

PCR amplification using the optimised conditions for primers Apis2F/Apis-2-R targeting the cytb gene produced the expected 121-bp fragments only for A-lineage A. $m$. iberiensis honeybees. The absence of amplification for the remaining $A$. mellifera subspecies of $\mathrm{M}$ and $\mathrm{C}$ lineages evidenced the specificity of these primers for A-lineage honeybees, namely A. m. iberiensis (Fig. 1A). Therefore, the applicability of the cytb primer set to detect A-lineage mtDNA in honey was further assayed, firstly in honey samples with known entomological origin (Fig. 1B), and subsequently in a wide range of commercial national and international honeys (Fig. 1B and Table 1). The first assay was performed with four honey samples of known entomological origin (samples A-D), which were produced by A. $m$. iberiensis (A lineage) from Portugal and from southern Spain, by A. m. iberiensis (M lineage) from north-eastern Spain and by $A$. $m$. ligustica (C lineage) from Italy. As expected, only the honey samples from A. m. iberiensis (A lineage) produced the 121-bp fragment (Fig. 1B), which confirms the specificity of the assay and its applicability to identify the entomological origin of honey. The proposed methodology was then applied to the analysis of 20 commercial honey samples acquired in 9 different EU countries, allowing the identification of A-lineage honeybees only for the four commercial honeys from Portugal (\#16 to \#19) and one from Spain (\#20) (Fig. 1B and Table 1). These results are in agreement with the natural and known distribution of honeybees of A lineage ancestry in the EU, namely the presence of $A$. m. iberiensis (A lineage) in the southwestern part of the Iberian Peninsula (Chávez-Galarza et al., 2017). Pinto et al. (2013) identified a total of 32 haplotypes among the 786 colonies of A. mellifera from Portugal, from which 28 were from A lineage, three from $\mathrm{M}$ lineage and only one from $\mathrm{C}$ lineage. As expected, samples purchased in other countries, rather than Portugal and Spain, gave negative results for PCR amplification with this primer set.

Regarding the primers targeting the COI gene (Aml5/Aml5-R), the 
PCR amplification results using the optimised conditions revealed the expected fragments of $151 \mathrm{bp}$ for most the honeybee specimens tested in this work (Fig. 2A). The weak amplification of A. m. mellifera and A. $m$. iberiensis ( $M$ lineage) can be explained by the existence of 3 mismatches in the forward primer (Aml5-F) (Fig. S1, supplementary data). Therefore, the experimental results highlight a high specificity of the designed COI primers for C-lineage A. mellifera, although the subspecies belonging to other lineages were also amplified. Considering the nucleotide differences between subspecies of the $C$ and $M$ lineages, the application of HRM was further exploited to allow its potential for $A$. mellifera subspecies discrimination (Druml \& Cichna-Markl, 2014).

\subsection{Real-time PCR coupled to HMR analysis}

A real-time PCR assay using EvaGreen dye, COI primers and melting curve analysis was applied to A. mellifera subspecies and melting data was further analysed by HRM. Considering the successful identification of A-lineage honeybees with the PCR assay targeting the cytb gene (Apis2-F/Apis2-R), the HRM approach aimed to differentiate the Clineage (A. m. carnica, A. m. ligustica and Buckfast) and M-lineage (A. $m$. mellifera and A. $m$. iberiensis) honeybees. The real-time PCR results showed that all honeybee specimens were successfully amplified, even in the cases that end-point PCR gave faint bands or even negative amplification, with Cq values in the ranges of 15.5-19.0 and 27.0-30.7 for lineages $\mathrm{C}$ and $\mathrm{M}$, respectively (Table 2). The analysis of the conventional melting curves for the obtained amplicons showed very close melt peaks $\left(73.0-73.4^{\circ} \mathrm{C}\right)$, without being possible to differentiate any group of the referred four A. mellifera subspecies (Fig. 3A). Therefore, melting data were further analysed using the Precision Melt Analysis software, which showed the differences among the melting curves in a normalised plot (Fig. 3C) that were evidenced in the temperatureshifted difference curve chart (Fig. 3E). This allowed discriminating the honeybees from the $\mathrm{C}$ and $\mathrm{M}$ lineages with levels of confidence above 99\% (Table 2). A. m. carnica, A. m. ligustica, and Buckfast honeybees, all corresponding to $\mathrm{C}$-lineage, were included in the same group (Cluster 1 ), which was defined as the reference cluster, with levels of confidence $\geq 99.4 \%$. Cluster 2 comprised the specimens of A. m. mellifera and A. $m$. iberiensis, both from $M$ lineage, with levels of confidence $\geq 99.0 \%$ (Table 2 and Fig. 3E). The applicability of the proposed methodology to differentiate honeybees from $\mathrm{C}$ and $\mathrm{M}$ lineages was then assayed with honeys of known entomological origin, collected by beekeepers in apiaries of $A$. m. iberiensis (M lineage) and of A. m. ligustica (C lineage). The results proved the ability of the proposed HRM method in establishing the entomological origin of honey produced by $A$. $m$. ligustica that was clustered with C-lineage honeybees (A. m. ligustica, A. m. carnica and Buckfast) and honey produced by $A$. $m$. iberiensis that was in cluster 2 together with M-lineage honeybees (A. m. iberiensis and A. $m$. mellifera) (Fig. 3B, D, F and Table S3, supplementary material). The high confidence levels $(\geq 99.0 \%$ ) evidenced the feasibility of the proposed method for honey testing, allowing to establish its entomological origin at the lineage level (Table S3, supplementary material).

The developed method was subsequently applied to the analysis of 15 commercial honey samples from different European countries that gave negative amplification with primers Apis2-F/Apis2-R targeting $c y t b$ gene. The obtained results of real-time PCR coupled to HRM analysis are summarised in Table 3, evidencing that most of the tested honey samples belong to mtDNA C-lineage. As expected, all honey samples from Italy and Croatia were grouped with C-lineage honeybees since A. m. ligustica and A. m. carnica are native from these countries, respectively (Ruttner, 1988). On the contrary, the honey samples from France, Denmark and Sweden were expected to belong to M-lineage since A. m. mellifera is native to those countries (Ruttner, 1988), but they were placed in C-lineage cluster. As mentioned, currently, A. m. mellifera is considered as a threatened subspecies in some European regions due to the massive introduction of foreign queens of C-lineage ancestry (Jensen et al., 2005; Pinto et al., 2014). Particularly in the Scandinavian countries, many beekeepers have shown their preference for A. m. ligustica, A. m. carnica or hybrid strains such as Buckfast (Jensen et al., 2005). This can explain the results obtained for those honey samples and supports the need for conservation strategies of native honeybees that, besides controlled breeding programs, can include marketing strategies to valorise the honey produced by autochthonous honeybees and by implementing measures to inform consumers. The French sample (\#7) was labelled as being honey from EU and non-EU, being grouped in the C-lineage cluster. Since China is the largest honey producer in the world, the "non-EU honey" label often refers to admixtures with Chinese honey. Accordingly to the label, and considering that most of professional Chinese beekeepers prefer A. $m$.

Table 2

Results of qualitative PCR and real-time PCR with HRM analysis applied to the analysis of different subspecies of honeybees.

\begin{tabular}{|c|c|c|c|c|c|c|c|c|}
\hline Honeybee & Lineage & Origin & \multicolumn{3}{|c|}{ End-point PCR } & $\begin{array}{l}\text { Real-time PCR } \\
-\mathrm{Cq} \pm \mathrm{SD}^{*}\end{array}$ & \multicolumn{2}{|l|}{ HRM } \\
\hline A. m. carnica & $\mathrm{C}$ & Serbia & + & - & + & $17.09 \pm 0.04$ & 1 & $100.0 \pm 0.1$ \\
\hline A. m. carnica & C & Serbia & + & - & + & $14.98 \pm 0.02$ & 1 & $100.0 \pm 0.0$ \\
\hline A. m. carnica & C & Serbia & + & - & + & $15.03 \pm 0.04$ & 1 & $100.0 \pm 0.1$ \\
\hline A. m. ligustica & C & Italy & + & - & + & $17.58 \pm 0.10$ & 1 & $99.9 \pm 0.1$ \\
\hline A. m. ligustica & C & Italy & + & - & + & $16.93 \pm 0.05$ & 1 & $99.8 \pm 0.1$ \\
\hline Buckfast & C & Portugal & + & - & + & $19.00 \pm 0.05$ & 1 & $99.9 \pm 0.0$ \\
\hline Buckfast & C & Portugal & + & - & + & $16.07 \pm 0.14$ & 1 & $99.8 \pm 0.1$ \\
\hline A. m. mellifera & $\mathrm{M}$ & The Netherlands & + & - & \pm & $27.98 \pm 0.18$ & 2 & $99.3 \pm 0.3$ \\
\hline A. m. mellifera & $\mathrm{M}$ & Norway & + & - & \pm & $27.01 \pm 0.20$ & 2 & $99.8 \pm 0.1$ \\
\hline A. m. mellifera & $\mathrm{M}$ & France & + & - & - & $28.59 \pm 0.17$ & 2 & $98.6 \pm 0.2$ \\
\hline A. m. mellifera & $\mathrm{M}$ & France & + & - & - & $30.67 \pm 0.32$ & 2 & $99.0 \pm 0.2$ \\
\hline A. m. iberiensis & $\mathrm{M}$ & Spain & + & - & \pm & $28.04 \pm 0.29$ & 2 & $99.5 \pm 0.3$ \\
\hline
\end{tabular}

* mean values \pm standard deviation (SD) of $n=3$ replicates; $(+)$ positive amplification; $(-)$ negative amplification; $( \pm)$ faint bands; amplification was performed using primers.

a 18 SEU-F/18SEU-R targeting eukaryotes,

b Apis2-F/Apis2-R targeting A. m. iberiensis of A lineage,

c Aml5-F/Aml5-R targeting A. mellifera. 
A

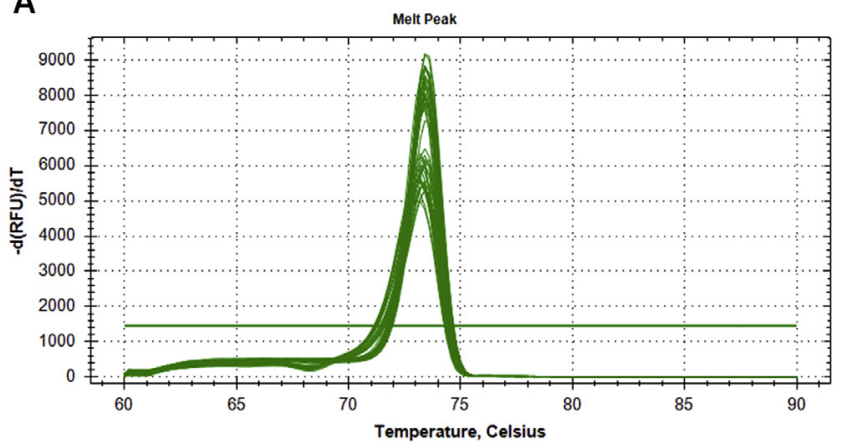

C

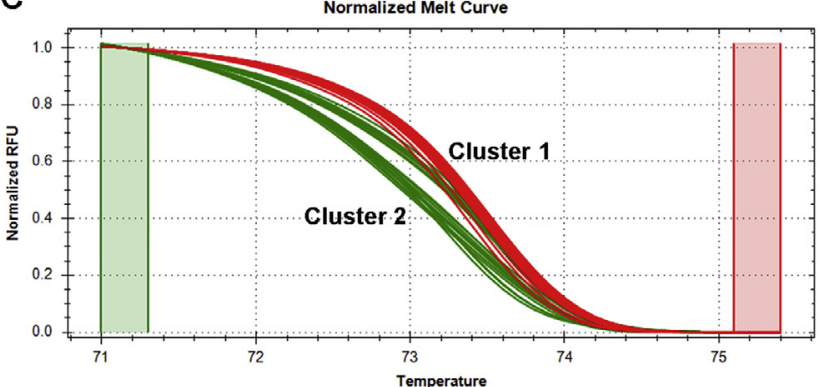

E

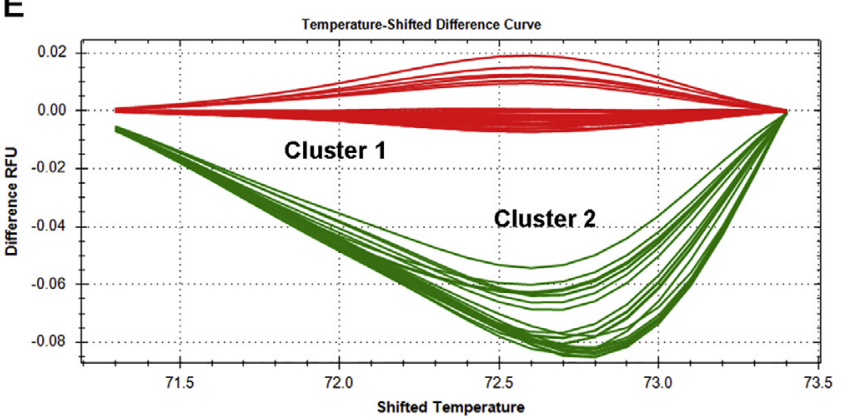

B

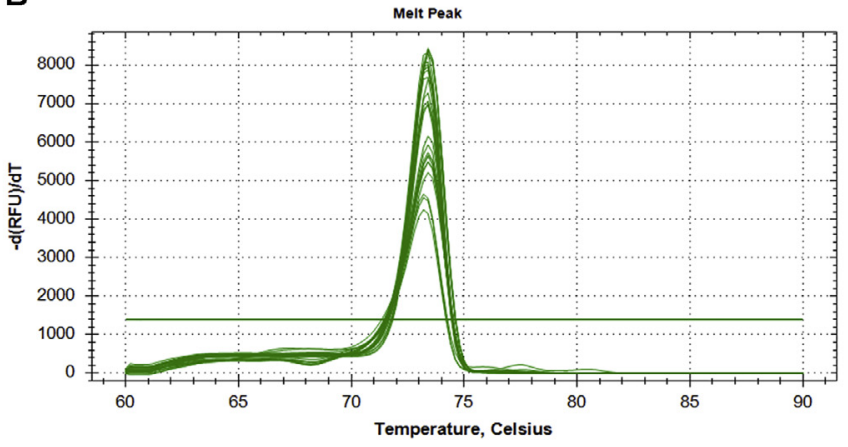

D

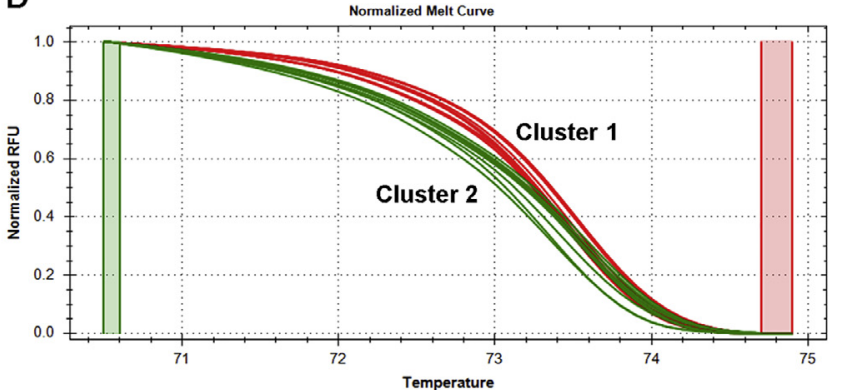

$\mathbf{F}$

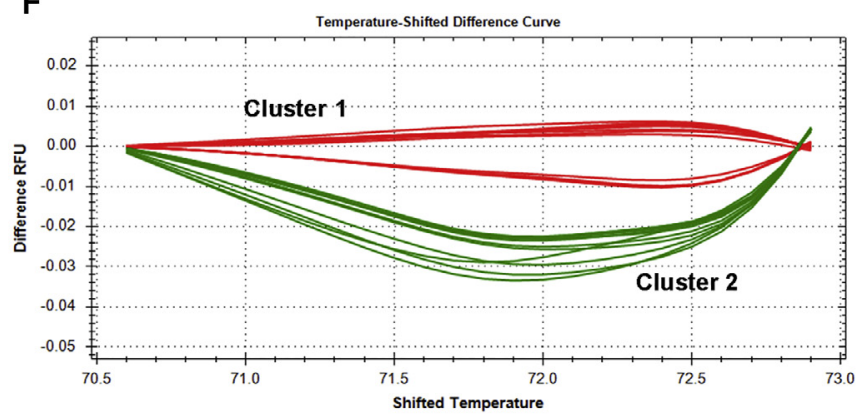

Fig. 3. Conventional melting curves (A, B), normalised melting curves (C, D) and difference curves (E, F) obtained by real-time PCR amplification with EvaGreen dye and HRM analysis targeting the COI gene applied to A. mellifera subspecies ( $\mathrm{n}=4$ replicates). Legend (C, E): cluster 1, C-lineage A. mellifera subspecies (A. $m$. carnica from Serbia and Croatia, A. m. ligustica from Italy, Buckfast from Portugal); cluster 2, M-lineage A. m. mellifera subspecies (A. $m$. mellifera from Norway, France and The Netherlands, and A. m. iberiensis from Spain). Legend (D, F): cluster 1, C-lineage A. mellifera subspecies (A. m. carnica, A. $m$. ligustica, Buckfast) and honey from A. m. ligustica (Italy); cluster 2, M-lineage A. m. mellifera subspecies (A. m. mellifera and A. m. iberiensis) and honey from A. m. iberiensis of M lineage (Spain).

Table 3

Results obtained by qualitative PCR and real-time PCR with HRM analysis targeting the COI gene of A. mellifera applied to the analysis of authentic and commercial honey samples from different European countries.

\begin{tabular}{|c|c|c|c|c|c|}
\hline \multirow[t]{2}{*}{ Honey sample } & \multirow[t]{2}{*}{ Labelled origin } & \multirow{2}{*}{$\begin{array}{l}\text { End-point } \\
\text { PCR }^{\mathrm{a}}\end{array}$} & \multirow{2}{*}{$\begin{array}{l}\text { Real time PCR } \\
\mathrm{Cq} \pm \mathrm{SD}^{\mathrm{b}}\end{array}$} & \multicolumn{2}{|l|}{ HRM } \\
\hline & & & & Cluster/Lineage & Level of confidence $\pm \mathrm{SD}(\%)^{\mathrm{b}}$ \\
\hline A & Borriol (M-lineage authentic honey), Spain & \pm & $34.1 \pm 0.4$ & M & $99.1 \pm 0.6$ \\
\hline B & Monteu Roero (C-lineage authentic honey), Italy & + & $29.2 \pm 0.1$ & $\mathrm{C}$ & $95.3 \pm 1.0$ \\
\hline 1 & EU and non-EU, Donji Dragonožec, Hrvatska, Croatia & + & $30.4 \pm 0.1$ & $\mathrm{C}$ & $95.1 \pm 1.1$ \\
\hline 2 & Helsingør, Denmark & + & $28.4 \pm 0.0$ & $\mathrm{C}$ & $98.3 \pm 1.0$ \\
\hline 3 & Nationalpark Thy, Denmark & + & $26.5 \pm 0.1$ & $\mathrm{C}$ & $99.5 \pm 0.1$ \\
\hline 4 & Pyrenees, Chemin de Berdoulou, France & + & $23.8 \pm 0.1$ & $\mathrm{C}$ & $99.7 \pm 0.0$ \\
\hline 5 & Provence, France (PGI honey) & + & $28.5 \pm 0.5$ & $\mathrm{C}$ & $99.1 \pm 0.3$ \\
\hline 6 & Provence, France (PGI honey) & + & $29.9 \pm 0.2$ & $\mathrm{C}$ & $99.3 \pm 0.1$ \\
\hline 7 & EU and non-EU, Maurecourt, France & + & $30.2 \pm 0.1$ & $\mathrm{C}$ & $99.2 \pm 0.6$ \\
\hline 8 & Riserva San Massimo, Milan, Italy & \pm & $29.8 \pm 0.1$ & $\mathrm{C}$ & $99.1 \pm 0.4$ \\
\hline 9 & Monteu Roero, Italy & + & $30.0 \pm 0.0$ & $\mathrm{C}$ & $99.8 \pm 0.2$ \\
\hline 10 & Centro-sud, Casabianca Asti, Italy & + & $29.3 \pm 0.0$ & $\mathrm{C}$ & $99.4 \pm 0.3$ \\
\hline 11 & Parco del Ticino, Milan, Italy & + & $31.8 \pm 0.1$ & $\mathrm{C}$ & $99.4 \pm 0.3$ \\
\hline 12 & EU and non-EU, Poland, Romania, Bulgaria, Ukraine & + & $32.1 \pm 0.1$ & M & $98.3 \pm 1.0$ \\
\hline 13 & Valencia, Spain & \pm & $33.1 \pm 0.2$ & M & $97.9 \pm 0.4$ \\
\hline 14 & Haugen, Sweeden & + & $27.7 \pm 0.4$ & $\mathrm{C}$ & $99.9 \pm 0.0$ \\
\hline 15 & Säffle, Sweeden & + & $28.0 \pm 0.1$ & $\mathrm{C}$ & $98.4 \pm 0.1$ \\
\hline
\end{tabular}

a amplification was performed using primers Aml5-F/Aml5-R targeting A. mellifera;

b mean values \pm standard deviation (SD) of $n=3$ replicates; (+) positive amplification; (-) negative amplification; $( \pm$ ) faint bands. 
ligustica honeybees because of their high productivity (Zheng, Wei, \& Hu, 2011), sample (\#7) can possibly be a mixture with Chinese honey. The Polish honey sample (\#12), grouped in the M-lineage cluster, also declares containing non-EU honey, which can be attributed to Ukraine since this is one of the countries mentioned on the label (Poland, Romania, Bulgaria and Ukraine). In these countries A. m. mellifera of $\mathrm{M}$ lineage ancestry is the predominant sub-species, justifying the obtained result. Finally, the commercial honey sample produced in Spain (\#3) was grouped in the M-lineage cluster, which is an expected result since Valencia is located in north-east of Spain, where A. m. iberiensis colonies of M lineage ancestry are predominant (Cánovas, De la Rúa, Serrano, \& Galián, 2008; Chávez-Galarza et al., 2017).

\section{Conclusions}

Honey is considered a product very prone to suffer economically motivated adulterations. While several works focused on the detection of frauds related to honey's botanical/and or geographical origin, only scarce work is available regarding its entomological origin. In this work, two DNA-based approaches are proposed to authenticate the entomological of European honeys, targeting the mitochondrial genes $c y t b$ and COI. A cytb subspecies-specific PCR assay was developed for the identification of A. m. iberiensis honeybees belonging to the A lineage (Portugal and Spain), being successfully validated with honeys of known entomological origin and applied to the authentication of commercial honeys. From 20 commercial honeys, 5 Portuguese and Spanish samples were confirmed as being from A-lineage A. m. iberiensis honeybees. To differentiate honeybees from A. mellifera of $\mathrm{C}$ and $\mathrm{M}$ lineages, a second method was proposed based on real-time PCR coupled to HRM targeting the COI gene. Similarly, the method was validated with authenticated honeys and applied to differentiate $\mathrm{C}$ ( $A$. $m$. ligustica and A. m. carnica) and M (A. m. iberiensis and A. m. mellifera) lineage honeybees in commercial samples from different European countries. Most of the analysed samples (13 out of 15) were identified as being from C-lineage honeybees. As expected, honeys from Italy and Croatia were identified as C-lineage honeybees since $A$. $m$. ligustica and A. m. carnica are native from these countries. However, in countries such as France, Denmark and Sweden where A. m. mellifera M-lineage are native, the honeys were also identified as being from $C$ lineage. This finding highlight the preference of honey beekeepers for $\mathrm{C}$ lineage instead of their native $\mathrm{M}$ lineage honeybees, endangering the autochthonous subspecies $A$. m. mellifera.

The present work demonstrated that DNA-based methods can provide accurate and powerful tools for the entomological honey authentication at the subspecies/lineage level.

\section{Conflict of interest}

None.

\section{Acknowledgments}

The authors are grateful to Dora Henriques for assembling the mitogenomes and to Pilar de la Rua and António Pajuelo for supplying authentic honey samples. This work was supported by FCT (Fundação para a Ciência e Tecnologia) through project UID/QUI/50006/2013 POCI/01/0145/FEDER/007265 with financial support from FCT/MEC through national funds and co-financed by FEDER, under the Partnership Agreement PT2020 and by the projects NORTE-01-0145FEDER-000011 and BeeHappy - POCI-01-0145-FEDER-029871 (financed by FEDER through the COMPETE 2020 - Operational Programme for Competitiveness and Internationalisation (POCI) and FCT). S. Soares, L. Grazina and J. Costa are grateful to FCT grants (SFRH/BD/75091/2010, SFRH/BD/132462/2017 and SFRH/BPD/ $102404 / 2014$, respectively) financed by POPH-QREN (subsidised by FSE and MCTES).

\section{Appendix A. Supplementary data}

Supplementary data to this article can be found online at https:// doi.org/10.1016/j.foodchem.2018.12.119.

\section{References}

Cánovas, F., De la Rúa, P., Serrano, J., \& Galián, J. (2008). Geographical patterns of mitochondrial DNA variation in Apis mellifera iberiensis (Hymenoptera: Apidae). Journal of Zoological Systematics and Evolutionary Research, 46(1), 24-30.

Chávez-Galarza, J., Garnery, L., Henriques, D., Neves, C. J., Loucif-Ayad, W., Jonhston, J. S., \& Pinto, M. A. (2017). Mitochondrial DNA variation of Apis mellifera iberiensis: Further insights from a large-scale study using sequence data of the tRNAleu-cox2 intergenic region. Apidologie, 48, 533-544.

Chen, R., Jiang, L.-Y., \& Qiao, G.-X. (2012). The effectiveness of three regions in mitochondrial genome for aphid DNA barcoding: A case in Lachininae. PLoS ONE, 7(10), e46190.

Costa, J. S. B. (2013). Development and application of molecular-based methods for the detection of tree nut allergens: The cases of almond, hazelnut and walnut. $\mathrm{PhD}$ thesisPorto: Faculty of Pharmacy, University of Porto.

Dall'Olio, R., Marino, A., Lodesani, M., \& Moritz, R. F. A. (2007). Genetic characterization of Italian honeybees, Apis mellifera ligustica, based on microsatellite DNA poly morphisms. Apidologie, 38(2), 207-217.

De la Rúa, P., Jaffé, R., Dall'Olio, R., Muñoz, I., \& Serrano, J. (2009). Biodiversity, conservation and current threats to European honeybees. Apidologie, 40(3), 263-284.

Directive 2014/63/EU of The European parliament and of the Council of 15 May 2014 amending Council Directive 2001/110/EC relating to honey (2014). Official Journal of the European Union, L164, pp. 1-5.

Druml, B., \& Cichna-Markl, M. (2014). High resolution melting (HRM) analysis of DNA Its role and potential in food analysis. Food Chemistry, 158, 245-254.

European Commission. 2017. Agriculture and Rural Development DOOR. Available from: http://ec.europa.eu/agriculture/quality/door/list.html. Accessed December 2017.

Fajardo, V., González, I., Martín, I., Rojas, M., Hernández, P. E., García, T., \& Martín, R (2008). Real-time PCR for detection and quantification of red deer (Cervus elaphus), fallow deer (Dama dama), and roe deer (Capreolus capreolus) in meat mixtures. Meat Science, 79(2), 289-298.

FAO. (2001). Revised codex standard for honey (No. CODEX STAN 12-1981), Rev. 1 (1987). Codex alimentarius, 11(Rev. 2), pp. 1-8.

Fernandes, T. J. R., Costa, J., Oliveira, M. B. P. P., \& Mafra, I. (2017). DNA barcoding coupled to HRM analysis as a new and simple tool for the authentication of Gadidae fish species. Food Chemistry, 230, 49-57.

Garnery, L., Cornuet, J. M., \& Solignac, M. (1992). Evolutionary history of the honey bee Apis mellifera inferred from mitochondrial DNA analysis. Molecular Ecology, 1, $145-154$.

Garnery, L., Franck, P., Baudry, E., Vautrin, D., Cornuet, J. M., \& Solignac, M. (1998). Genetic diversity of the west European honey bee (Apis mellifera mellifera and A. $\mathrm{m}$. iberica). I. Mitochondrial DNA. Genetics Selection Evolution, 30(1), S49-S74.

Garrison, E., \& Marth, G. (2012). Haplotype-based variant detection from short-read sequencing. arXiv:1207.3907 [q-bio.GN]. Available from https://arxiv.org/abs/1207. 3907. Accessed March 2017.

Hebert, P. D., Cywinska, A., Ball, S. L., \& deWaard, J. R. (2003). Biological identifications through DNA barcodes. Proceedings of the Royal Society B: Biological Sciences, 270, 313-321.

Jensen, A. B., Palmer, K. A., Boomsma, J. J., \& Pedersen, B. V. (2005). Varying degrees of Apis mellifera ligustica introgression in protected populations of the black honeybee, Apis mellifera mellifera, in northwest Europe. Molecular Ecology, 14(1), 93-106.

Kek, S. P., Chin, N. L., Tan, S. W., Yusof, Y. A., \& Chua, L. S. (2017). Molecular identification of honey entomological origin based on bee mitochondrial 16S rRNA and COI gene sequences. Food Control, 78, 150-159.

Li, H., Gao, J., Liu, H., \& Cai, W. (2009). Progress in the researches on insect mitochondrial genome and analysis of gene order. Science Foundation in China, 17, $39-45$.

Mafra, I., Silva, S. A., Moreira, E. J. M. O., da Silva, C. S. F., Beatriz, M., \& Oliveira, P. P. (2008). Comparative study of DNA extraction methods for soybean derived food products. Food Control, 19(12), 1183-1190.

Meixner, M. D., Costa, C., Kryger, P., Hatjina, F., Bouga, M., Ivanova, E., \& Büchler, R. (2010). Conserving diversity and vitality for honeybee breeding. Journal of Apicultural Research, 49(1), 85-92.

Meixner, M. D., Pinto, M. A., Bouga, M., Kryger, P., Ivanova, E., \& Fuchs, S. (2013). Standard methods for characterising subspecies and ecotypes of Apis mellifera. Journal of Apicultural Research, 52(4), 1-28.

Pinto, M. A., Henriques, D., Chávez-Galarza, J., Kryger, P., Garnery, L., van der Zee, R., Johnston, J. S. (2014). Genetic integrity of the Dark European honeybee (Apis mellifera mellifera) from protected populations: A genome-wide assessment using SNPs and mtDNA sequence data. Journal of Apicultural Research, 53(2), 269-278.

Pinto, M. A., Henriques, D., Neto, M., Guedes, H., Muñoz, I., Azevedo, J. C., \& De la Rúa P. (2013). Maternal diversity patterns of Ibero-Atlantic populations reveal further complexity of Iberian honey bees. Apidologie, 44, 430-439.

Prosser, S. W. J., \& Hebert, P. D. N. (2017). Rapid identification of the botanical and entomological sources of honey using DNA metabarcoding. Food Chemistry, 214, 183-191.

Ramón-Sierra, J. M., Ruiz-Ruiz, J. C., \& de la Luz Ortiz-Vázquez, E. (2015). Electrophoresis characterisation of protein as a method to establish the entomological origin of stingless bee honeys. Food Chemistry, 183, 43-48. 
Ruttner, F. (1988). Biogeography and Taxonomy of Honeybees. Heidelberg, Berlin, New York: Springer Verlag284.

Sambrook, J., Fritsch, E. F., \& Maniatis, T. (1989). Molecular Cloning (2nd ed.). Cold Spring Harbor Laboratory Press: New York.

Soares, S., Amaral, J. S., Oliveira, M. B. P. P., \& Mafra, I. (2015). Improving DNA isolation from honey for the botanical origin identification. Food Control, 48, 130-136.

Soares, S., Amaral, J. S., Oliveira, M. B. P. P., \& Mafra, I. (2017). A comprehensive review on the main honey authentication issues: Production and origin. Comprehensive Reviews in Food Science and Food Safety, 16, 1072-1100.

Soares, S., Grazina, L., Mafra, I., Costa, J., Pinto, M., Duc, H., ... Amaral, J. (2018b). Novel diagnostic tools for Asian (Apis cerana) and European (Apis mellifera) honey authentication. Food Research International, 105, 686-693.

Soares, S., Grazina, L., Costa, Amaral, J., Oliveira, M., \& Mafra, I. (2018). Botanical authentication of lavender (Lavandula spp.) honey by a novel DNA-barcoding approach coupled to high resolution melting analysis. Food Control, 86, 367-373.

Villa, C., Costa, J., Oliveira, M. B. P. P., \& Mafra, I. (2017). Novel quantitative real-time PCR approach to determine safflower (Carthamus tinctorius) adulteration in saffron (Crocus sativus). Food Chemistry, 229, 680-687.

Zheng, H., Wei, W., \& Hu, F. (2011). Beekeeping industry in China. Bee World, 88(2), $41-44$. 